American Journal of

Health, Medicine and Nursing Practice (AJHMN)

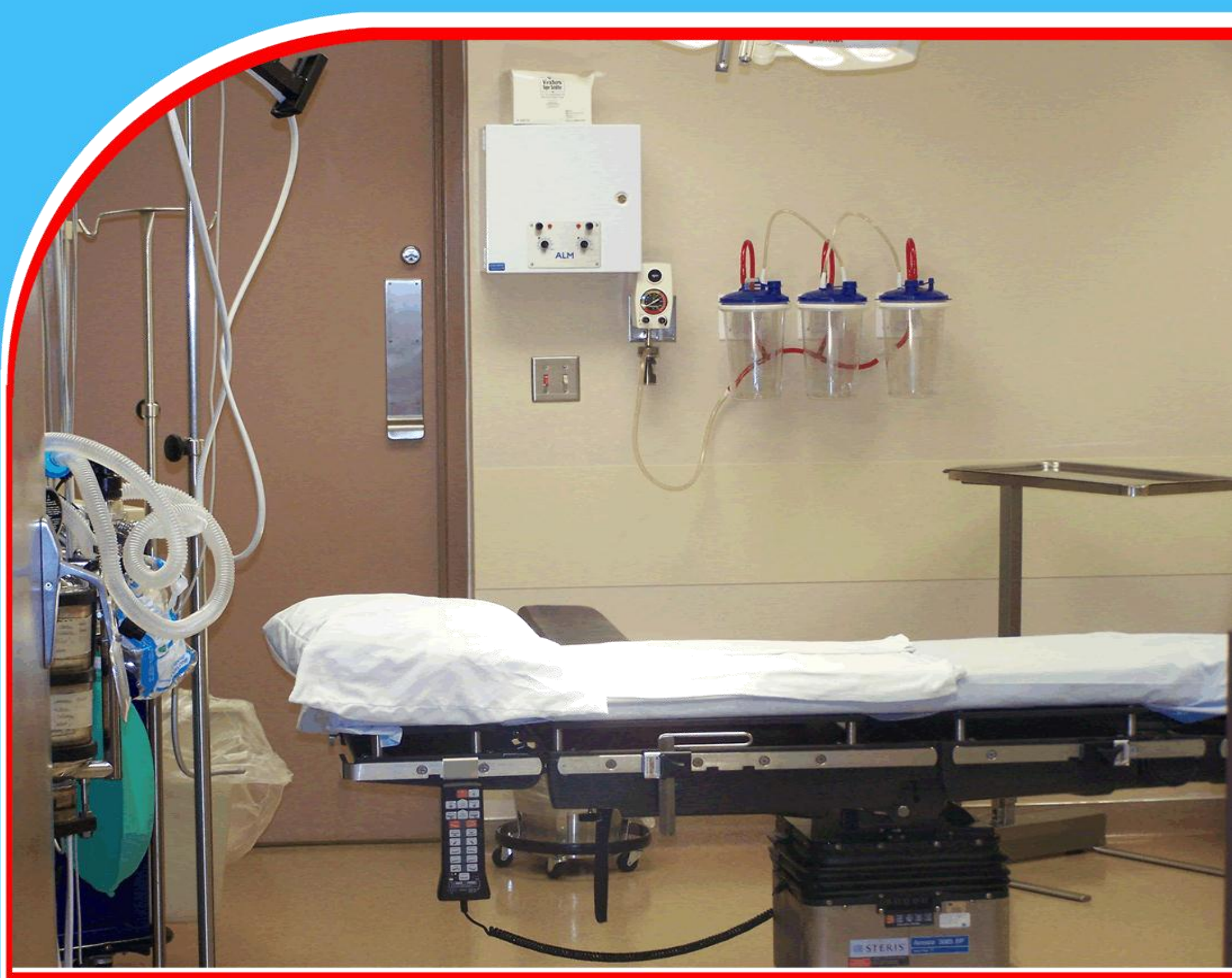

Initial Probing In Children Presenting At the Age of Three To Four Years

Muhammad Israr, Khalil Khan Zahir, Adnan Khattak, and Irfanullah Khattak

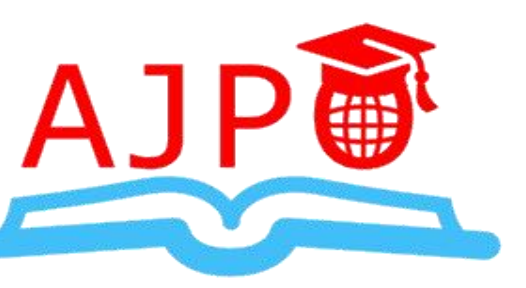


American Journal of Health, Medicine and Nursing Practice

ISSN 2520-4017 (Online)

Vol.7, Issue 3, pp $16-20,2022$

$\underline{\text { www.ajpojournals.org }}$

\title{
Initial Probing In Children Presenting At the Age of Three To Four Years
}

\author{
1*Muhammad Israr, ${ }^{2}$ Khalil Khan Zahir, ${ }^{3}$ Adnan Khattak, ${ }^{4}$ Irfanullah Khattak \\ ${ }^{1,2}$ Fellow Pediatric Ophthalmology HMC Peshawar, Pakistan. \\ ${ }^{3}$ Health Department KPK, Pakistan \\ ${ }^{4}$ Specialist Registrar Ophthalmology, HMC, Peshawar, Pakistan. \\ *Corresponding Author's Email: docisrar88@yahoo.com
}

\begin{abstract}
Objective: The aim of this study is to find out the ration of success in the initial probing for the congenital nasolacrimal duct obstruction at age $25^{\text {th }}$ month to $60^{\text {th }}$ month.

Methodology: The study was prospective non-comparative interventional case series. The study included 59 eyes of 47 patients who visited the Ophthalmology HMC Peshawar in 2020. The patients were labelled as CNLDO with history of epiphora and or discharge since birth or first few days of life. The diagnosis was confirmed with evaluation in which it was assessed that there is no other associated adnexal issue like conjunctively congestion. Examination also included tear meniscus height and resurge test.

Results: In prospective non-comparative interventional case series 52 eyes of 41 patients between the ages of 25 to 60 months with CNLDO were probed. Most of the patients were females i.e. 27. Most of the obstructions were of complex type i.e. 32 while 20 patients were of membranous type. Patients with bilateral CNLDO were 11. Successes ratio of probing in membranous type of obstruction was $90 \%$ i.e. 18 eyes got cured while two eyes needed repeated probing. While in case of complex obstruction the success ratio was, $32.2 \%$ i.e. only 10 patients got cured out of 32 patients. Overall success ratio was $54 \%$ i.e 28 of 54.
\end{abstract}

Conclusion: Children presenting with congenial nasolacrimal duct obstruction in older ages should be probed initially.

Keywords: Initial probing, children, under, 3/4 year 
American Journal of Health, Medicine and Nursing Practice

ISSN 2520-4017 (Online)

Vol.7, Issue 3, pp $16-20,2022$

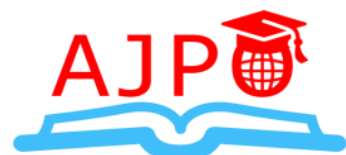

www.ajpojournals.org

\section{INTRODUCTION}

Congenital nasolacrimal duct obstruction is one of the common problems in the children presenting in the early years of life ${ }^{1}$. Most of the children get cured in the first year of life with the conservative management. The conservative management is lacrimal massage and topical antibiotics. The children in which the problem persists are treated with probing under general anesthesia in early days of their lives ${ }^{2}$. Some of the authors are of the view that success ratio of probing for congenital nasolacrimal duct obstruction decreases with increasing age $\mathrm{e}^{3,4,5}$. While other claim that increasing age has no significant effect on failure ratio of probing. ${ }^{6-9}$ Several studies suggest that success rate of probing depends upon the type of obstruction i.e whether simple membranous or complex. ${ }^{10,11}$ Two hypothesis have been proposed for the higher ratio of failure with congenital nasolacrimal obstruction in the children presenting late. According to one hypothesis prolong inflammation and fibrosis in the lacrimal drainage system due to increasing age is the cause of failure of probing while another hypothesis suggests that as the simple obstruction clears spontaneously and the complex obstructions persist, thereby increasing failure ratio of probing ${ }^{5,8}$. The aim of this study is to find out the ration of success in the initial probing for the congenital nasolacrimal duct obstruction at age $25^{\text {th }}$ month to $60^{\text {th }}$ month.

\section{METHODS}

The study was prospective non-comparative interventional case series. The study included 59 eyes of 47 patients who visited the Ophthalmology HMC Peshawar in 2020. The patients were labelled as CNLDO with history of epiphora and or discharge since birth or first few days of life. The diagnosis was confirmed with evaluation in which it was assessed that there is no other associated adnexal issue like conjunctively congestion. Examination also included tear meniscus height and resurge test. Those with history of previous probing, trauma, punctual agenesis, and associated other ocular diseases were not included. Patients were educated with the procedure and consent was obtained. The researcher performed probing under general anesthesia. After dilatation of lower punctum, the Bowmann's probe was introduced into the punctum and rotated laterally and advanced till it touch the bony firmness. It was then slightly withdrawn and rotated at 90 degree and advanced till the probe was stopped when breakthrough was felt. The patients were seen 1 week, 1 month and 3 months. They were evaluated for the resolution of symptoms and regurge.

\section{RESULTS}

In prospective non-comparative interventional case series 52 eyes of 41 patients between the ages of 25 to 60 months with CNLDO were probed. Most of the patients were females i.e. 27. Most of the obstructions were of complex type i.e. 32 while 20 patients were of membranous type. Patients with bilateral CNLDO were 11. Successes ratio of probing in membranous type of obstruction was 90\% i.e. 18 eyes got cured while two eyes needed repeated probing. While in case of complex obstruction the success ratio was, $32.2 \%$ i.e. only 10 patients got cured out of 32 patients. Overall success ratio was $54 \%$ i.e 28 of 54 . 
American Journal of Health, Medicine and Nursing Practice

ISSN 2520-4017 (Online)

Vol.7, Issue 3, pp $16-20,2022$

WWW.ajpojournals.org

Table 01: Results of this study have been mentioned in following

\begin{tabular}{lllll}
\hline AGE (MONTHS) & TOTAL & COMPLEX & MEMBRANOUS & CURED \\
\hline $25-36$ & 20 & 12 & 7 & 11 \\
$37-48$ & 18 & 11 & 7 & 9 \\
$49-60$ & 14 & 9 & 6 & 8 \\
\hline & 52 & 32 & 20 & 28 \\
\hline
\end{tabular}

\section{DISCUSSION}

Probing is the gold standard therapeutic procedure in patients with congenital nasolacrimal duct obstruction. However, there is a controversy regarding the procedure from age point of view. Some of studies suggest to perform it in the first year of life. While other prefer to keep the patient on conservative management i.e. lacrimal massage and topical antibiotics during the first year of life, while procedure should be performed in second year of life in those children who persist the pathology. There is extensive literature on the use of probing in the management of childhood epiphora, and the rates of probing success are between 86 and 96\% in mainly retrospective case series in the first year of life ${ }^{12-15}$. These are impressive figures for any surgical procedure; however, these results must be viewed in light of a condition that has been shown in both retrospective series and prospective cohort observational studies to have a spontaneous resolution rate of between 89 and $96 \%$ by one year of age. ${ }^{16,17}$.

Sturrock et al., ${ }^{11}$ reported a success rate of $72 \%$ in the second year and $42 \%$ in children more than 2 years of age ${ }^{18}$ stated a cure rate of $54 \%$ in children probed after 2 years of age. MacEven et al., ${ }^{19}$ found a cure rate of $85 \%$ in a combined probing and nasal endoscopy among 40 children 10-89 months of age. Mannor et al., ${ }^{3}$ found a negative correlation between the age and the success of probing. Katowitz and $\mathrm{Welsh}^{4}$ believed that increasing age after 13 months not only decreases the cure rate but also increases the number and complexity of future procedures. In sharp contrast to those reports, Robb $^{6}$ Zwaan et al., ${ }^{9}$, and El-Mansoury and et al., ${ }^{8}$ found more than $90 \%$ success rate in late and very late probing for CNLDO. Some authors reported an insignificant effect of the increasing age on the success rate of initial probing after the age of 12 months ${ }^{6-8}$ However, the issue of complex CNLDO was not noted in their reports.

Two factors were incriminated in the lower cure rate with probing in older children. It was suggested that it might be a result of chronic infection and fibrosis with increasing age ${ }^{4,13}$. While Paul and shepherd ${ }^{5}$ assumed that lower success in older children might be due to a self-selection process. These children may represent the pool of children with more complicated type of obstruction. Kashkouli et al., ${ }^{10}$ and Honavar et al., ${ }^{22}$ showed that the complex CNLDO was more likely to be found in older children, with subsequent lower success rate. Kushner ${ }^{23}$ even suggested that a reasonable approach to older children with a CNLDO is to plan a probing procedure with possible alternative surgical plans if a complex obstruction is found. 
American Journal of Health, Medicine and Nursing Practice ISSN 2520-4017 (Online)

Vol.7, Issue 3, pp $16-20,2022$

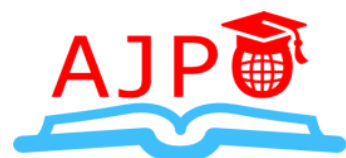

www.ajpojournals.org

In this study we found that most of the obstruction type in congenital nasolacrimal duct obstruction was of complex type i.e. 32/52. While the simple membranous were of smaller ratio 20/52. The success ratio in the complex type was $32.2 \%$ while that of membranous type was $90 \%$. This outcome of probing in complex and membranous is comparable to study done by Kashkouli et al 10. So the statistical analysis of this study shows that increase in failure ratio of probing in patients presenting late is due the fact that the complex type of congenital nasolacrimal duct obstruction are more likely to be found in older children.

Overall success ratio of probing in children of age 25 months to 60 months is $50 \%$. i.e half of the patients who underwent probing under G/A were cured while half retained the complaint. Based on this finding, simplicity, and low rate of complication, very late probing could be considered as an initial surgical step in the management of CNLDO. And the parents of patients who are found to have complex type of congenital nasolacrimal duct obstruction should be counselled about the poor prognosis and the possible another procedure like closed intubation or dacrosystorhinostomy.

\section{CONCLUSION}

Conclusion is that children presenting with congenial nasolacrimal duct obstruction in older ages should be probed initially.

\section{REFERENCES}

1. MacEwen CJ, Young JDH. Epiphora during the first year of life. Eye 2020;5(Pt 5):596600

2. Nelson LB, Calhoun JH, Menduke H. Medical management of congenital nasolacrimal duct obstruction. Ophthalmology 2019; 92(9):1187-90.

3. Mannor GE, Rose GE, Frimpong-Ansah K, et al. Factors affecting the success of nasolacrimal duct probing for congenital nasolacrimal duct Obstruction. Am J Ophthalmol 2020; 127(5):616-17

4. Katowitz JA, Welsh MG. Timing of initial probing and irrigation in congenital nasolacrimal duct obstruction. Ophthalmology2018; 94(6):698-705.

5. Paul TO, Shepherd R. Congenital nasolacrimal duct obstruction: natural history and the timing of optimal intervention. J Pediatr Strabismus 2018; 31(6):362-7.

6. Robb RM. Success rate of nasolacrimal duct probing at time intervals after 1 year of age. Ophthalmology 2018;105(7):1307-9.

7. Zwaan J. Treatment of congenital nasolacrimal duct obstruction before and after the age of 1 year. Ophthalmic Surg Lasers 2017; 28(11):932-6

8. El-Mansoury J, Calhoun JH, Nelson LB, et al. Results of late probing for congenital nasolacrimal duct obstruction. Ophthalmology 2016; 93(8):1052-4

9. Cifici F, Akman A, Sonmez M, et al. Systematic, combined treatment approach to nasolacrimal duct obstruction in different age groups. Eur J Ophthalmol 2000;10(4):3249 
10. Kashkouli MB, Beigi B, Parvaresh MM, et al. Late and very late initial probing for congenital nasolacrimal duct obstruction: What is the cause of failure? Br J Ophthalmol 2018; 87(9):1151-3

11. Sturrock SM, MacEwen CJ, Young JDH. Long term results after probing for congenital nasolacrimal duct obstruction. Br J Ophthalmol 2021; 78(12):892-4.

12. Robb R, Probing and irrigation for congenital nasolacrimal duct obstruction, Arch Ophthalmol, 2016;104:378-9.

13. Baker JD, Treatment of congenital naso-lacrimal duct obstruction, J Pediatr Ophthalmol Strabismus, 2016;22:34-5.

14. Koke MP, Treatment of occluded naso-lacrimal ducts in infants, Arch Ophthalmol, 2016;43:750-54.

15. Kashkouli MB, Kassaee A, Tabatabaee Z, Initial nasolacrimal duct probing in children under age 5: cure rate and factors affecting success, J Pediatr Ophthalmol Strabismus, 2021;6:360-63

16. MacEwen CJ, Young JDH, Epiphora during the first year of life, Eye, 2018;5:596-600.

17. Price HW, Dacryostenosis, J Pediatr, 2021;30:302-5

18. Young JDH, MacEwen CJ, Ogston SA. Congenital nasolacrimal duct obstruction in second year of life: a multicenter trial of management. Eye 2015;10:485-91

19. Value of nasal endoscopy and probing in the diagnosis and management of children with congenital epiphora.

20. Honavar SG, Prakash VE, Rao GN. Outcome of probing for congenital nasolacrimal duct obstruction in older children. Am J Ophthalmol 2000; 130: 42-8.

21. Kushner BJ. The management of nasolacrimal duct obstruction in children between 18 months and 4 years old. J AAPOS 2020; 2: 57-60. 